\title{
SOCIOLOGIA DE UM EDUCADOR - PASCHOAL LEMME E A EDUCAÇÃO DE ADULTOS
}

\author{
SOCIOLOGY OF AN EDUCATOR \\ - PASCHOAL LEMME AND ADULT EDUCATION \\ SOCIOLOGÍA DE UN EDUCADOR \\ - PASCHOAL LEMME Y LA EDUCACIÓN DE ADULTOS
}

Cristiane Fernanda Xavier ${ }^{\mathrm{I}}$

\begin{abstract}
Resumo Análise da figuração de Paschoal Lemme em sua interdependência com outras pessoas e grupos no processo de sua militância e produção intelectual em favor da educação de adultos. À luz das proposições eliasianas, o exame documental aponta que para Lemme a criação de um sistema público de ensino democrático estava subordinada à mudança das condições sociais da população. Por entender que a qualificação do trabalhador redundaria na melhoria da sua situação material e favoreceria a sua participação, na perspectiva de Lemme a educação de adultos era tida como um dos componentes capazes de operar em prol das transformações sociais necessárias à democratização do ensino. Vinculado ao comunismo, trabalhou pela revolução burguesa face os limites das possibilidades impostas à revolução operária. Mas as tensões e os conflitos envolvidos na validação das ideias sugerem que, no decorrer do processo social, a identificação de Lemme com a ideologia marxista e a sua proximidade com os comunistas concorreram para interditar a penetração das suas posições em circuitos sociais mais amplos.
\end{abstract}

Palavras-chave: Paschoal Lemme; Educação de adultos; Figuração; Norbert Elias.

Abstract Analysis of figuration created by Paschoal Lemme in his interdependence with other people and groups in the process of his militancy and intellectual production in favor of adult education. Based on Eliasian propositions, the exploration of documents suggests that for Lemme the creation of a democratic system of public education was subordinated

I Universidade Federal de Alfenas (UNIFAL-MG) Alfenas/MG Brasil. 
to the change in the social conditions of the population. On the understanding that the qualification of the worker would improve his material situation and would favor his conditions of participation; in Lemme's perspective, adult education was considered as one of the components capable of operating in the social transformations necessary for the democratization of education. Linked to communism, he worked for the bourgeois revolution against the limits of the possibilities imposed on the workers' revolution. But the tensions and conflicts involved in the validation of ideas suggest that, in the course of the social process, Lemme's identification with marxist ideology and his closeness to the communists contributed to interdict the penetration of his positions in broad social circuits.

Key-words: Paschoal Lemme; Adult Education; Figuration; Norbert Elias.

Resumen Análisis de la figuración de Paschoal Lemme en su interdependencia con otras personas y grupos en el proceso de su militancia y producción intelectual en favor de la educación de adultos. A la luz de las proposiciones eliasianas, el examen documental apunta que para Lemme la creación de un sistema público de enseñanza democrático estaba subordinada al cambio de las condiciones sociales de la población. Por entender que la calificación del trabajador redundaría en la mejora de su situación material y favorecería su participación, en la perspectiva de Lemme la educación de adultos era considerada como uno de los componentes capaz de operar en favor de las transformaciones sociales necesarias para la democratización de la enseñanza. Vinculado al comunismo, trabajó por la revolución burguesa frente a los límites de las posibilidades impuestas a la revolución obrera. Pero las tensiones y conflictos involucrados en la validación de las ideas sugieren que, en el proceso social, la identificación de Lemme con la ideología marxista y su proximidad con los comunistas concurrieron para interdictar la penetración de sus posiciones en circuitos sociales más amplios.

Palabras clave: Paschoal Lemme; Educación de adultos; Figuración; Norbert Elias.

\section{INTRODUÇÃo}

As décadas que antecederam a ampla Campanha de Educação de Adolescentes e Adultos (CEAA) ${ }^{1}$ foram marcadas por variadas ações e acontecimentos relevantes para a compreensão a respeito do modo como o trabalhador foi reconhecido como sujeito de direitos e como a educação dos adultos foi incorporada ao sistema educacional brasileiro. Esse processo de longa data teve no Império dois marcos importantes: o fim do regime escravista e a promulgação da Lei 3.029, de 1881 (Lei Saraiva). Tendo em conta esses acontecimentos, em conformidade com Angela de Castro Gomes (2005), enquanto o trabalho fora valorizado como fator de regeneração social na medida em que garantia uma ocupação,

1 A CEAA, primeira iniciativa da União destinada à educação dos trabalhadores, foi lançada em 1947 e funcionou até 1963. Em linhas gerais, a literatura especializada, entre as quais figuram Celso de Rui Beisiegel (2004) e Vanilda Paiva (2003), considera que embora a CEAA estivesse orientada por uma perspectiva mais ampliada de educação, na prática a Campanha concretizou-se por uma abordagem do problema da educação de adultos restrita à alfabetização e ao domínio de técnicas de trabalho. 
tirava os homens da miséria e os afastava dos vícios; a instrução dos trabalhadores fora considerada como a via para a participação. Ou seja, nessa dinâmica, esforços foram realizados para a criação de uma ética do trabalho com a finalidade de legitimar o trabalhador como um ator social e político.

Já na República, a atuação das esquerdas no movimento operário (e no pós-1930, do Ministério do Trabalho) ampliou a visibilidade dos trabalhadores como sujeitos de direitos, bem como, estimulou a demanda pela extensão da oferta de educação aos adultos. A partir de 1934, face à promulgação de quase todas as leis que passaram a regular as relações de trabalho no Brasil, o sindicalismo assumiu destacada relevância e a associação entre participação política e instrução foi acentuada (GOMES, 2005).

Ao lado da defesa de que a instrução era o caminho para a participação, desenvolveu-se um crescente apelo por reformas educacionais e combate ao analfabetismo. $\mathrm{O}$ gradativo realce da figura do trabalhador como portador do direito de participar da vida política e social e de usufruir das riquezas materiais e simbólicas, que ele ajudou a construir, encontrou eco nas demandas por modernidade e civilização e nas questões relativas à democratização do ensino que embalavam o movimento brasileiro de renovação pedagógica.

É que nesse período, conforme aponta Diana Vidal (2008), parte representativa de educadores e intelectuais estava envolvida na discussão política relativa à necessidade de tornar efetivamente pública a educação e quanto ao estabelecimento da escola nos preceitos escolanovistas. Em função da inclusão do ensino religioso (de frequência facultativa) nas escolas públicas no texto da Constituição Federal de 1934, as divergências entre as duas principais posições ideológicas em confronto no terreno educacional foram radicalizadas. De um lado, a dos partidários da escola pública, única, obrigatória, gratuita e laica, e de outro, a corrente dirigida pela Igreja Católica.

Nesse contexto, enquanto ideologias entram em disputa na Europa diante da ameaça fascista, na cena política brasileira o momento também era conturbado. Rodrigo Patto Sá Motta (2002) afirma que nos idos de 1934 o Governo Vargas já se encontrava desgastado. Uma série de greves eclodiu no país e a fragilidade do sistema partidário nacional contribuiu para a continuidade do poder oligárquico regional. A normalidade institucional decorrente da promulgação da Constituição de 1934 veio acompanhada do crescimento das atividades de grupos situados à esquerda ou à direita do espectro. Desde então, comunistas ${ }^{2}$ e integralistas ${ }^{3}$ viram suas organizações aumentarem, ao mesmo tempo em que se engalfinhavam. A militância política radical foi estimulada e uma série de campanhas contra o fascismo foi desencadeada.

2 A Aliança Nacional Libertadora (ANL) foi uma organização política de âmbito nacional de estreitas relações com o comunismo, fundada oficialmente em 1935, e cuja atuação culminou na Revolta Comunista. Sua plataforma inclúa o combate ao "fascismo, ao imperialismo, ao latifúndio e à miséria" (MOTTA, 2002).

3 Aglutinados sob o lema "Deus, Pátria e Família", a Ação Integralista Brasileira (AIB) - movimento nacional de orientação fascista, fundada em 1932, por Plinio Salgado - "se propôs a combater o liberalismo, o socialismo, o capitalismo internacional e as sociedades secretas vinculadas ao judaísmo e à maçonaria" (TRINDADE, 2001: 2.811). 
As dissidências verificadas na arena política, de certa forma, misturavam-se àquelas em curso no terreno educacional. Isso porque, além da educação ter ocupado um lugar estratégico nas propostas de reconstrução nacional, boa parte da intelectualidade engajada nas lutas políticas e ideológicas da época militava na Associação Brasileira de Educação (ABE) e ocupava cargos diretivos no meio educacional.

Em meio à agitação do período, entrou em jogo a luta pela definição do modelo de política pública pela qual a União deveria assumir a organização da educação de adultos. Ocorre que, além dos pontos assinalados, o Ministério da Educação e Saúde (MES) incumbiu o Conselho Nacional de Educação (CNE) de constituir uma comissão especial para elaborar um Plano Nacional de Educação (PNE), no qual a oferta do ensino primário contemplasse os adultos; orientação ratificada no artigo 150 da Constituição de 1934.

Nessa disputa, Paschoal Lemme (1904-1997) foi um dos educadores que se colocaram no centro do debate. Assim sendo, o objetivo deste trabalho é apresentar resultados de pesquisa dedicada à compreensão da figuração formada pelo educador Paschoal Lemme em sua interdependência com outras pessoas e grupos, evidenciando a sua militância e produção intelectual em prol da educação de adultos.

\section{Pensando com Elias a sociologia de Paschoal Lemme}

No plano teórico, a pesquisa fundamentou-se no modelo de análise desenvolvido por Norbert Elias, mais especificamente em "Mozart - sociologia de um gênio" (ELIAS, 1995). Por meio de análise documental, neste trabalho Elias elucida os problemas que o compositor Mozart encontrou durante a sua vida em articulação ao quadro das pressões sociais que agiam sobre o artista e a sua produção, destacando a sua interdependência com outras figuras sociais da época.

Para compreender a obra de Mozart, nessa perspectiva, Elias explica que foi necessário considerar as correlações entre o seu desenvolvimento pessoal e o desenvolvimento social da posição de artista. Ou seja, foi necessário considerar a convergência (ou divergência) entre as inclinações e objetivos pessoais e as exigências da posição de artista, no contexto do seu tempo e em relação aos grupos sociais dos quais participou. Daí Elias informar que a vida de Mozart é um exemplo de "como a situação de grupos burgueses outsiders, numa economia dominada pela aristocracia de corte e num tempo em que o equilíbrio de forças ainda era favorável ao establishment cortesão, mas não a ponto de suprimir todas as expressões de protesto", afetou a sua obra e a estrutura da sua personalidade. Segundo o autor, a existência social de Mozart movia-se em dois mundos: o ambiente "não cortesão" de seus pais e o dos aristocratas da corte. Como tal, ao mesmo tempo em que Mozart desprezava a sociedade de corte, ele produzia suas músicas em sintonia com os círculos aristocráticos e também desejava que sua obra fosse reconhecida pela sociedade de corte. Assim, a música de Mozart fora modelada pelo padrão musical das sociedades de corte hegemônicas na Europa numa relação paradoxal ao seu "descortês habitus social" (ELIAS, 1995, p. 16). 
À relação de interdependência entre indivíduos que formam sociedades, Elias chamou de "figuração". Por esse conceito, o autor afirma que as sociedades não são nada mais que figurações de homens interdependentes. "Não existe sociedade fora dos indivíduos que a constituem e os indivíduos que a constituem não existem fora da sociedade que formam em sua convivência mútua" (ELIAS, 2001, p. 43). Desse ponto de vista, as figurações formadas pelas pessoas são as vias pelas quais se compreende a experiência social, a maneira como o indivíduo se comporta, quais são as suas ideias, o que defende e o que propõe.

As redes de interdependência constituem, pois, os espaços sociais onde as pessoas constroem suas relações. Tais relações contêm níveis de integração operados por forças reticulares expressas tanto pela razão como por ideologias, imprevistos, acasos e até mesmo por adesões e refrações inconscientes. Por integrar o processo de formação e desenvolvimento das ideias, sensibilidades, preferências e repulsas, tal multiplicidade de referenciais requer considerar os condicionantes sociais que envolveram cada indivíduo desde a sua infância. Para Elias, a historicidade de cada indivíduo, da infância à sua idade adulta, é a história das suas relações de interdependência com outras pessoas e funções e contém a síntese daquilo que chamamos de sociedade. O estudo dessa historicidade é a chave para a compreensão das ideias e dos comportamentos humanos, num dado contexto social.

Considerando que as relações sociais são operadas em interdependência no plano grupal e no âmbito da individualidade, no interior dessa dinâmica é que têm origem e se difundem as formas de contenção sobre as "forças instintivas", que, por amor, medo dos outros, vergonha, embaraço e pelo autocontrole, conformam os comportamentos, sentimentos, pensamentos e objetivos dos indivíduos; processo ao qual Elias chamou de individualização. O funcionamento geral dos mecanismos de controle e autocontrole dá-se pelas formas particulares que cada indivíduo elabora uma ideia ou conduta que não existia ou se apropria e leva adiante aquelas que já circulavam socialmente em algum tempo, passado ou presente. Isso significa que a formação e o trânsito de modos de ser e de pensar são orientados por situações de grupo de todos os tipos: familiar, de vizinhança, religiosa, profissional, de um partido político ou de uma associação.

Daí que, para Elias (2001), homem algum é absolutamente livre ou absolutamente determinado. Nas redes de interdependência, quanto maior for o poder de um indivíduo sobre outro(s), maior será a sua margem de manobra (esfera de ação da individualização) e por isso tanto maior será o escopo da sua individualização. No entanto, à medida que o poder de um indivíduo abre espaço para decisões individuais, também impõe limites à sua margem de decisão em função da sua interdependência com outras figuras sociais.

De acordo com Cynthia Greive Veiga (2013), a articulação simultânea entre o estudo das alterações do comportamento do indivíduo (psicogênese) e o estudo das mudanças sociais (sociogênese) constitui o traço típico do pensamento eliasiano. A autora explica que também o sociólogo Karl Mannheim e o historiador Karl Lamprecht foram pensadores que atribuíram importância à dimensão psíquica dos indivíduos no desenvolvimento do conhecimento. "Para estes autores as estruturas da psique humana, as estruturas da socie- 
dade humana e as estruturas da história humana são indissociavelmente complementares, só podendo ser estudadas em conjunto" (VEIGA, 2013, p. 2).

Georg Simmel foi outro estudioso que pensou a relação indivíduo e sociedade de modo processual, de efeitos mútuos. Segundo Leopoldo Waizbort (1999), na proposição de Simmel "descobrir as relações mínimas entre os homens" significa tomá-las como "formas formadoras da sociedade". Assim como "as interações aparentemente menores estabelecem a conexão da unidade social, as diligências imensamente pequenas dispõem o nexo da unidade histórica" (SIMMEL, 1908 apud WAIZBORT, 1999, p. 95).

Podemos dizer que as proposições eliasianas estão inscritas no debate acerca da relação indivíduo e sociedade, desenvolvido especialmente no campo sociológico. Em grande medida, esse debate é motivado pela consideração de que a baliza teórica que sustenta a produção do conhecimento nas ciências sociais tem sido marcadamente informada por uma perspectiva dualista de análise que postula uma separação entre sujeito e objeto. Ou o sujeito está sozinho (e autônomo) em um mundo de objetos ou os objetos falam por si de modo absoluto. Em outras palavras, ora as análises sociológicas apresentam-se centradas no sistema, desconsiderando o mundo do sujeito, ora mostrando um mundo subjetivo sem sistema. Desse dilema decorreu a elaboração de trabalhos que buscaram superar tal dualismo. No lugar de separar sujeito e objeto, indivíduo e sociedade, sociedade e natureza, considera-se que há uma permanente e complexa interação entre essas instâncias.

Temos, portanto, que a experiência social, as ideias e o comportamento do educador e intelectual Paschoal Lemme são norteados por todos os tipos de situações de grupo existentes nas suas múltiplas redes de interdependência. Assim sendo, ao buscar compreendê-lo de modo enredado a sua historicidade emergiu com a história do seu tempo e em relação aos grupos sociais dos quais participou.

Quanto às fontes, as Memórias de Paschoal Lemme foram utilizadas como ponto de partida e como uma espécie de plataforma no trabalho de pesquisa. Tal como o registro memorialístico que materializa a história de Lemme e dos seus grupos de pertencimento, também foram tomadas como fontes: livros, artigos, entrevistas, relatórios, decretos, leis, comunicados, revistas, dados estatísticos, jornais de época e estudos sobre a temática da educação de adultos realizados por membros da ABE.

Ao conferir às memórias um papel norteador no processo de pesquisa, há que se considerar o problema do uso do relato autobiográfico como prova documental. Compreende-se que subjetividade, sinceridade, singularidade e ambição de veracidade são dimensões constitutivas da escrita memorialística. Afinal, a memória resulta das lembranças de uma pessoa específica e não de outra, resulta das impressões que essa pessoa específica tem do seu próprio passado; passado que pessoa alguma viveu. Contudo, tomá-las com confiança e lhes atribuir honestidade não extingue o problema da legitimidade na narrativa autobiográfica.

Ocorre que, em conformidade com Gomes (2004), se a sinceridade na produção do eu não pode ser confundida com a verdade dos fatos; a verdade por sua vez não existe em qualquer tipo de documento. Isso porque "sinceridade, como os demais sentimentos, estão submetidos a mecanismos de contenção e aceitação social. É nesse sentido que a escrita 
de si se torna uma prática cultural estratégica para um equilíbrio, sempre precário, entre expressão e contenção de si (...) e que se manifestam nas muitas formas consagradas de se escrever cartas, diários, memórias" (GOMES, 2004, p. 17).

Temos, portanto, que o documento sempre contém uma dimensão monumental. Assim como aponta Jacques Le Goff (2003), para além do seu significado aparente, o "documento/monumento" é uma expressão das relações de poder em curso num dado contexto, das quais resultam escolhas, seleções e formas intencionais (ou não) de deixar registrados os conteúdos da realidade. Nesse sentido, a narrativa memorialística resulta de uma atividade que revela, esquece, sublinha, relativiza, modifica, adapta, revisa e cria. Como tal, é constituída no esforço de montar e impor, consciente ou inconscientemente, determinada imagem da história, da sociedade e dos grupos que a formaram para ser perpetuada.

Em favor da "boa memória", Paul Ricoeur (2007) considera que "nada temos de melhor que a memória para garantir que algo ocorreu antes de formarmos sua lembrança". Mas adverte: "Será tão necessário resistir (...) à tentação de dissolver o fato histórico na narração e esta numa composição literária indistinguível da ficção, quanto é preciso recusar a confusão inicial entre fato histórico e acontecimento real rememorado". Daí o autor propor a "escolha da verdade mais justa" na tarefa de autenticar as declarações testemunhais. Isto é, ultrapassar a busca da verdade e a busca do bem, introduzindo a justiça na noção de verdade. Para tanto, faz-se necessário trazer à tona a diversidade das interpretações possíveis no plano histórico (RICOEUR, 2007, p. 189).

A partir da orientação de levantar possibilidades interpretativas razoáveis para o objeto investigado, o tratamento das fontes se deu sobre três planos correlacionados: o condicionamento social, o conteúdo específico do documento e o cotejo de dados entre os documentos. O processo de investigação também levou em conta o contexto social e histórico de produção das fontes, os objetivos e destinatários, temas e problemas em discussão, argumentação e a retórica do remetente.

\section{Educação de adultos e democratização da sociedade no Projeto Político-Pedagógico de Paschoal Lemme}

No contexto do movimento de renovação pedagógica dos anos de 1920-1930, a participação de Paschoal Lemme no debate sobre o problema da educação de adultos foi edificada na disputa entre construir um sistema adequado de instrução capaz de mudar as condições sociais ou mudar as condições sociais para criar um sistema adequado de instrução. Para tornar possível a democratização do ensino, enquanto a escolarização das crianças fora enfatizada nas reformas educacionais do Distrito Federal, Lemme afirmava que a educação de adultos ultrapassava em premência e importância a própria obra de extensão do ensino elementar para os indivíduos em idade escolar. Para Lemme, a educação de adultos cumpriria um papel estratégico em favor das mudanças sociais; condição que ele considerava sine qua non à democratização do ensino. Por entender que o trabalhador qualificado impulsionaria a equidade material e participaria na vida social e política, na base da con- 
formação do pensamento social de Lemme, a educação de adultos era prioritária (LEMME, 1937a; 1937b; 1938).

Na perspectiva de Lemme, o analfabetismo e a pouca escolaridade dos trabalhadores eram as consequências inevitáveis de uma estrutura social injusta e desigual que atingia os pobres, impedindo-os de se dedicarem aos estudos. Além disso, considerava que a restrição da educação de adultos à oferta de cursos de alfabetização e técnicas de trabalho significava a oferta de uma formação comprometida com o fornecimento dos conhecimentos e pessoal necessário à maquinaria produtiva do sistema capitalista; gerando e transmitindo aos trabalhadores um quadro de valores que legitimava os interesses dominantes. ${ }^{4}$

Daí o educador ter insistido na assertiva de que o adulto aprende em função das suas necessidades reais, que aprende muito menos do que poderia aprender, porque em parte subestima a sua capacidade e em parte porque se sente constrangido por acreditar que já passou da idade de instruir-se. Lemme inscreveu a educação de adultos numa noção abrangente de educação cujo processo é permanente ao longo da vida. Em função disso, a educação de adultos envolveria ações formativas de natureza sistemática e assistemática.

Na proposição de Lemme, a educação assistemática ocupava um lugar privilegiado na formação dos adultos. Entendia que a flexibilidade curricular ampliava as condições de acesso dos trabalhadores à educação e conferia maior autonomia aos adultos na organização dos seus estudos, tendo em vista as suas demandas. Além disso, face ao reduzido número de escolas existentes, a oferta de educação assistemática asseguraria a possibilidade de continuidade nos estudos, bem como, alargaria a capacidade de matrícula ao estender os espaços de formação aos sindicatos, associações de classe, cooperativas, clubes ou outras agremiações.

Por entender que a escola era incapaz de abarcar todas as necessidades de aprendizagem do adulto e que a oferta de educação de adultos sistemática tinha como ênfase a alfabetização e a iniciação ao trabalho, a educação de adultos assistemática atuaria no aperfeiçoamento, atualização técnica e na qualificação política do trabalhador. Assim, ao afirmar a educação assistemática como parte constitutiva da educação de adultos, fundamentalmente Lemme também asseverava os limites do papel da educação sistemática na transformação social.

Ao lado da educação sistemática e assistemática, a extensão cultural completava o modelo de educação de adultos idealizado por Lemme. Considerava que o trabalhador tinha direito à informação e à recreação. Nessa perspectiva, atribuiu um papel pedagógi-

\footnotetext{
4 Dos anos de 1930 até a instalação da CEAA, diferentes modos de conceber o adulto analfabeto ou pouco escolarizado bem como, as suas necessidades de aprendizagem balizaram a disputa pelo modelo nacional de escolarização dos trabalhadores a ser adotado pelo Governo Federal. Em contraste com a proposição de Paschoal Lemme, destacam-se aquelas que vinculavam a educação de adultos à alfabetização de nível elementar e/ou profissional. Por exemplo, na proposta de Lourenço Filho (1933), as "escolas nacionaes", destinadas à educação primária, deveriam integrar a alfabetização à "educação higiênica, à educação para o trabalho e à educação para a compreensão dos direitos e deveres cívicos". Já para Everardo Backheuser (1936), a alfabetização dos adultos era, inclusive, desnecessária. Nesse sentido, as "universidades populares" propostas por Backheuser deveriam ser "itinerantes, rápidas e intensivas", destinadas ao aperfeiçoamento profissional e à formação moral, cívica, higiênica e religiosa do operário.
} 
co às artes e aos meios de comunicação na formação dos adultos. Concorriam para tal a instalação de bibliotecas públicas, fixas ou circulantes, museus, rádios, cinemas, teatros, exposições bem como, palestras e demonstrações. Tratava-se de incorporar o trabalhador à civilização moderna, de modo que pudesse gozar dos prazeres oferecidos pela cultura.

Em termos práticos, nos anos de 1930 Lemme organizou e dirigiu a educação de adultos no âmbito do poder público local do Distrito Federal e em 1946, sob a chancela do Partido Comunista do Brasil (PCB), participou da fundação da Universidade/Escola do Povo (TRIBUNA POPULAR, 02/02/1946, p. 3). Inspiradas nas universidades populares da Europa - "estabelecimentos que preenchiam os vazios que o ensino deixava na cultura dos trabalhadores dedicando-se ao intercâmbio de ideias e aprofundamento de problemas filosóficos, políticos e econômicos da vida social e nacional” (LEMME, 1937a, p. 12) - as duas experiências guardam muitas afinidades entre si e de certo modo a UP representou a continuidade dos trabalhos iniciados por Lemme no Distrito Federal e que foram interrompidos com a sua prisão, em $1936 .^{5}$

Naquele tempo, a educação de adultos do Distrito Federal estava estruturada de modo a oferecer simultaneamente "cursos elementares", "cursos de continuação, aperfeiçoamento e oportunidade" e "cursos de extensão cultural" com base na flexibilidade, em função dos interesses de grupos de alunos, sem formalidades especiais de matrícula, sem seriação rígida de matérias, sem horário fixo e com duração variável, segundo as necessidades e situações a que tenham de atender. ${ }^{6}$ A UP, por sua vez, proporcionava ensino gratuito, em cursos de continuação e aperfeiçoamento dos mais variados e cursos de extensão cultural, bem como, desenvolveu uma campanha de alfabetização de adultos com base em material didático próprio. $^{7}$

Nos dois casos, havia uma perspectiva alargada e continuada do processo de aprendizagem, na qual era preciso considerar uma disposição dos tempos e espaços educativos que facilitassem a frequência às atividades pelo trabalhador. Ao incluir a extensão cultural na constituição dessas experiências destacou-se o papel pedagógico das artes e dos meios de comunicação na formação dos adultos. Assim como o trabalho realizado nos cursos de continuação e aperfeiçoamento da Diretora de Educação de Adultos e Difusão Cultural do Distrito Federal foi interrompido, em 1936, sob a suspeita de atuarem em favor da divulga-

5 À época, Paschoal Lemme era responsável pela Diretoria de Educação de Adultos e Difusão Cultural; setor da Diretoria de Instrução Pública do Distrito Federal. Sua prisão se deu em meio às investigações realizadas pela Comissão Nacional de Repressão ao Comunismo. De acordo com relatório da Polícia Política, o programa dos cursos de educação de adultos da União Trabalhista - proposto por Valério Regis Konder, Paschoal Lemme e Edgar Sussekind de Mendonça - havia sido enviado a Arthur Ernest Ewert e Luís Carlos Prestes para aprovação. Consta ainda que os referidos proponentes eram membros do quadro social da ANL, com destacada atuação. A isso, o relatório acresce que fora apreendido um documento escrito de próprio punho e assinado por Prestes pelo qual indicava os nomes de Paschoal Lemme e Valério Konder, entre outros nomes relacionados, como as pessoas com as quais os revoltosos podiam contar, por ocasião da Revolta Comunista de 1935. Como resultado, em 14 de fevereiro de 1936, Lemme foi detido e preso por um período de 16 meses (Relatório da Polícia Política, 1937).

6 DISTRITO FEDERAL. Decreto 4.299, de 25 de julho de 1933 (JORNAL DO BRASIL, 26/07/1933, p. 8).

7 No âmbito das atividades da UP, Chave da leitura (para adultos), de Moisés Xavier de Araújo, foi uma cartilha especialmente elaborada para subsidiar a campanha de alfabetização de adultos. 
ção do marxismo, em 1957 a UP foi fechada em função de denúncias que a julgavam um núcleo de atividades comunistas. ${ }^{8}$

Talvez pela longevidade que alcançou e autonomia que dispunha em relação ao Estado, a UP tenha sido o modelo educativo que melhor traduziu o modo de organizar a educação de adultos para que exercesse a função de atuar no processo de democratização da sociedade, como concebido por Lemme. Ironicamente, a UP foi ativa durante o período de instalação, ascensão e declínio da CEAA. Nesse sentido, a UP resistiu como alternativa ao modelo de política pública nacional de educação de adultos implantado no Brasil e também permitiu que Paschoal Lemme seguisse lutando em defesa do seu projeto de sociedade.

\section{ENTRE TRAMAS: INTERDEPENDÊNCIAS, INDIVIDUALIZAÇÃO E FORMAÇÃO DAS SEN- Sibilidades, posições e defesas de Paschoal Lemme}

A maneira como Lemme se posicionou-se em relação à educação dos adultos está vinculada à sua identificação com uma perspectiva socialista de organização da sociedade. Como fruto da sua individualização, na medida em que complexificaram as suas redes de interdependência, Lemme foi acentuando as suas posições numa perspectiva mais orientada pelo materialismo. A construção desse vínculo foi tecida desde a sua infância e estendeu-se ao longo da vida. Nesse sentido, tanto as relações familiares quanto as profissionais e de militância tiveram aguda participação na elaboração da ideia de Paschoal Lemme sobre o papel da educação de adultos na democratização da sociedade.

Em conformidade com Elias (1994), como típico dos indivíduos das sociedades modernas que desenvolveram a necessidade de fixar uma personalidade singular para si em relação aos demais, Paschoal Lemme procurou ser um membro destacado nas suas redes de interdependência. Quarto filho de uma família numerosa, ele cresceu num ambiente familiar no qual ia aos poucos sendo confundido entre os novos irmãos que chegavam praticamente a cada ano. De modo diferente dos seus irmãos, não se interessou pela odontologia, como era o desejo do seu pai. Carente de atenção materna e deslocado dos irmãos em relação ao futuro profissional que o pai havia planejado, a escola tornou-se um espaço reconfortante para Lemme, diante do apoio e incentivo que recebia do professor Teófilo Moreira da Costa. Em contraste com as pressões sociais vividas em família, o reconhecimento do professor Teófilo conferia à autopercepção de Lemme os sentimentos de pertencimento social que integram a busca identitária dos indivíduos. E assim ele cursou o magistério, embora hesitante quanto ao prestígio social e a estabilidade financeira que a carreira lhe propiciaria.

Diante de algumas situações de constrangimento e embaraço experimentadas no início da carreira docente, Lemme cogitou abandonar o magistério. Tentou fixar-se no comér-

8 Em relação às repressões sofridas pela Instituição consta, por exemplo, que em abril de 1952, quando Paschoal Lemme compunha o Conselho Técnico-administrativo da Escola do Povo, esse Conselho veio a público manifestar repúdio às perseguições "policial-fascistas" sofridas pela Escola do Povo que, em dias anteriores havia sido invadida, dois dos seus professores apreendidos, cartilhas, fichários e papéis oficiais recolhidos e suas atividades interrompidas (DIÁRIO DE NOTÍCIAS, 19/04/1952, p. 3; IMPRENSA POPULAR, 20/04/1952, p. 4).

Comunicações | Piracicaba | v. $24 \mid$ n. $3 \mid$ p. 255-278| setembro-dezembro 2017 
cio de artigos dentários e também deu início ao curso de engenharia. Ao decidir se casar e assumir a sua independência, em relação aos pais, o magistério tornou-se a possibilidade concreta (e disponível) de transformar-se numa profissão especial e distinta. Distinção essa que "ocupa o mais alto lugar na escala de valores dessas sociedades e que garante ao indivíduo o respeito, o aplauso e, muitas vezes, o amor" (ELIAS, 1994, p. 119).

Dedicado profissional, ao longo da sua carreira procurou manter-se entre aqueles que se consideravam a vanguarda da intelectualidade carioca em relação aos grupos que avaliavam serem arcaicos e conservadores, como os católicos e os integralistas. Apesar de bastante citado na historiografia da educação brasileira, Paschoal Lemme não tem sido muito estudado. Do mesmo modo, poucas investigações se dedicaram a compreender a educação de adultos na perspectiva desse educador. No entanto, os resultados da pesquisa que sustenta o presente trabalho permitem afirmar que o envolvimento de Lemme nas lutas pela educação dos trabalhadores faz dele uma referência na história da educação de adultos no Brasil.

No âmbito das suas atividades profissionais desenvolvidas entre os anos de 1928 e 1936, em meio às diversas funções que exerceu e atividades que realizou na Diretoria de Instrução Pública do Distrito Federal, trabalhou como professor e vice-diretor em cursos populares noturnos durante a administração de Fernando de Azevedo; organizou e dirigiu a educação de adultos do Distrito Federal na gestão de Anísio Teixeira; foi diretor da educação de adultos do Distrito Federal na gestão de Francisco Campos. Nos anos de 1933 a 1936, atuou junto à educação de adultos como inspetor de ensino primário e profissional do Estado do Rio de Janeiro. Em 1938, por ocasião de concurso público do MES para o cargo de técnico da educação, Lemme sistematizou as suas ideias e posições em relação ao tema por meio de monografia intitulada "Educação de Adultos - uma experiência de cursos de continuação, aperfeiçoamento e oportunidade realizada no Distrito Federal". Tendo sido aprovado no referido concurso, trabalhou como funcionário do MES até a sua aposentadoria, em 1961.

Enquanto isso, militou em diferentes agremiações. Foi eleito membro do conselho diretor da ABE por diversas vezes. Em 1934, atuou na fundação do "Club de Cultura Moderna", organização ligada à ANL. No ano de 1935, com outros educadores e intelectuais, Lemme criou a revista Movimento. ${ }^{9}$ Foi colaborador em jornais como Tribuna Popular, órgão do PCB. Referências elogiosas ao seu nome, caráter e competência figuram nas páginas de A Batalha. Entre os anos de 1945 e 1947, período em que o PCB esteve na legalidade, assessorou o Partido junto à Câmara Federal e na Assembleia Legislativa do Distrito Federal nas questões relativas à educação. Concedeu entrevistas, publicou artigos na imprensa, enfim, procurou colocar suas ideias em circulação atribuindo um lugar de destacada relevância ao papel da educação de adultos no processo de democratização da sociedade.

Em suma, no contexto brasileiro da época, Lemme inovou ao difundir suas proposições políticas e educacionais fundadas na articulação entre educação, participação política e melhoria das condições econômicas dos trabalhadores como condição para "libertá-los das relações que os mantêm à margem do progresso e da civilização" (LEMME, 1937b: 7).

9 Revista do "Club de Cultura Moderna", Movimento combatia o fascismo e difundia os princípios da ideologia marxista. Arquivo Edgard Leuenroth (AEL/UNICAMP). 
Entre as formas de contestação pelas quais expressou suas defesas, a assinatura em manifestos foi a mais recorrente. Defendeu as suas posições toda vez que teve a oportunidade e basicamente por onde Lemme passou ele registrou o seu nome em algum protesto. Em outras ocasiões, ele próprio articulou as conveniências necessárias à exposição das suas ideias e projetos. Para tanto, entre várias figuras, notadamente contou com o apoio de Venâncio Filho, Edgar Sussekind de Mendonça, Armanda Álvaro Alberto, Antonio Lemme Junior, Humberto Lemme, Abel Lemme, Valério Konder, Moisés de Araújo, Pedro Gouveia Filho e Rui Guimarães de Almeida.

As convicções de Lemme e o seu apreço a valores igualitários, à democracia, à liberdade de pensamento e aos princípios da moderna pedagogia estiveram no âmago das relações sociais constituidoras das figurações às quais ele se filiou. Nasceu e cresceu em ambiente familiar de orientação espírita, o que significava naquela época ter sido educado sob a ordem da razão e da ciência em detrimento do preceito religioso. ${ }^{10} \mathrm{Na}$ vida profissional, foi defensor da escola pública, democrática e laica. Além de colaborar nas reformas educacionais do Distrito Federal, Lemme também encontrou no movimento de renovação pedagógica um ambiente que coadunava com algumas das suas referências familiares. Identificado com as ideias marxistas, passou a reconhecer a existência de uma íntima relação entre as desigualdades sociais e as desigualdades educacionais e, portanto, a reconhecer os limites da obra educacional no processo de democratização social. Ao se aproximar da militância comunista, assumiu definitivamente a convicção de que qualquer aspiração emancipatória não poderia dissociar a educação da ordem social mais ampla.

Nesse percurso, tornou-se um atuante educador de esquerda e um intelectual ${ }^{11}$ antifascista. Como tal, o anticlericalismo constituiu num traço comum; um elo entre as motivações que o levaram às diferentes formas de engajamento. Isso não significa que as suas sensibilidades, adesões e refrações tivessem, essencialmente, uma gênese espiritual. Significa

10 Fortemente socializado pela doutrina espírita, Lemme aprendeu que o "espiritismo kardecista era uma ciência universal" (LEMME, 2004, p. 144, v. 1). Ocorre que nas suas origens, o espiritismo aspirou reconhecimento acadêmico por considerar a alma como uma questão científica. Em função disso, proclamou-se instância da ciência experimental. Pretendeu demonstrar que, por meio da atividade mediúnica, era possível provar a existência dos espíritos e a sobrevivência da alma após a morte. Hippolyte-Léon-Denizard Rivail, que depois adotaria o nome de Alan Kardec, foi o codificador do espiritismo na França. De acordo com Mary del Priore (2014), em 1854, Rivail passou a se interessar pelo magnetismo e pelos fenômenos sobrenaturais. Estudou de forma racional e científica a fim de explicar por que as mesas volantes se moviam. Ao participar de sessões organizadas por sonâmbulos e seus magnetizados, passou a receber uma série de anotações oferecidas pelos sonâmbulos, bem como, a acrescentar informações a partir de questões que ele propunha às pessoas em transe. Em 1857, com o pseudônimo de Alan Kardec, publicou O livro dos espíritos, resultante dos seus estudos e cujo objetivo era apresentar as bases para o entendimento da "ciência espírita". Um ano depois, Kardec fundou a Revue Spirite, ainda hoje em circulação. Embora Paschoal Lemme e os irmãos tivessem sido educados sob os preceitos do espiritismo; isto é, sob os preceitos da razão e da ciência em detrimento do princípio religioso, não há evidências de que eles foram praticantes do espiritismo.

11 O conjunto das atividades e ações realizadas por Lemme permite associá-lo à ideia de um intelectual ao modo proposto por Jean-François Sirinelli (2003). De acordo com o autor, o intelectual é aquele indivíduo engajado na vida da cidade cuja "notoriedade eventual ou sua especialização, reconhecida na sociedade em que vive (especialização esta que legitima e mesmo privilegia sua intervenção no debate da cidade), põe-se a serviço da causa que defende" (SIRINELLI, 2003, p. 243).

Comunicações | Piracicaba | v. $24 \mid$ n. $3 \mid$ p. 255-278| setembro-dezembro 2017 
que, para Lemme, o poder de influência da igreja representava o conjunto das forças que atravancavam o progresso da ciência, o avanço da razão, a liberdade de ideias e de ação, representava o esteio das classes abastadas que dominavam e exploravam os fracos e os pobres como também representava o conjunto das vozes que desqualificavam e colocavam sob suspeita os valores que Lemme aprendera a honrar ainda na infância.

Nem todas as figurações de Lemme foram mapeadas na pesquisa em questão. Por força do objeto, apenas aquelas cujas fontes levantadas demonstraram alguma ligação do educador com a educação de adultos foram consideradas. Além disso, cumpre destacar que Paschoal Lemme não se dedicou exclusivamente ao problema da educação de adultos, bem como, não foi o único, entre os educadores que atuaram nas reformas educacionais do Distrito Federal, a se envolver com o comunismo. A despeito da sua simpatia em relação à ideologia marxista e da sua proximidade com os comunistas, parece que o posicionamento de Lemme não o colocava em confronto com a condução assumida pelos administradores das reformas educacionais do Distrito Federal dos anos de 1920 e 1930; reformas essas comumente tidas como de cunho liberal na literatura especializada. É que, segundo afirma Dermeval Saviani (2008), “àquela época não havia incompatibilidade entre 'liberais' e 'marxistas' na formulação de um projeto educacional. (...) todos os progressistas, inclusive os marxistas, tenderam a endossar o credo escolanovista" (SAVIANI, 2008, p. 92).

Nessa mesma direção, Aparecida Favoreto (2008) diz que escolanovistas e comunistas entendiam que os preceitos científicos eram importantes ao processo educacional em detrimento ao preceito religioso. Para uns, a religião representava um obstáculo ao progresso e, para outros, o progresso era uma etapa para alcançar a revolução operária. Comunistas e escolanovistas somavam-se na luta contra o passado "atrasado" e "antidemocrático". Defendiam uma educação laica, científica e ativa, criticavam o método repetitivo, a cultura literária e livresca, tida como predominante no período; reconheciam o analfabetismo como um entrave ao desenvolvimento e à escola como um direito.

Ocorre que, para os comunistas, o Brasil ainda não havia realizado a sua revolução burguesa e, em função disso, era preciso, primeiramente criar as condições para a revolução proletária. Daí a ideia de apoiar o desenvolvimento econômico capaz de romper com a miséria, com o atraso cultural e com o imperialismo e, desse modo, garantir o desenvolvimento livre das forças de produção como condições para a implantação da "verdadeira democracia”. Em função disso, a escola pública era necessária. Havia também o reconhecimento de que o homem não poderia renunciar às conquistas técnicas, científicas, artísticas e culturais já atingidas pelas forças de produção. O analfabetismo e a ignorância, por sua vez, eram considerados inimigos da revolução. Assim, ao mesmo tempo em que a escola era tida como incapaz de promover a revolução, a instrução e a educação das massas trabalhadoras eram elementos impulsionadores das transformações almejadas pelos comunistas.

Daí então que "aos intelectuais da época cabia fazer o que pudessem pela concretização da libertação dos explorados e oprimidos" (MOVIMENTO, n. 3, 1935, p. 8). A atuação de Lemme na educação de adultos esteve inscrita nesse contexto. No limite das possibilida- 
des impostas à revolução operária, trabalhar em prol da revolução burguesa foi o caminho encontrado por ele.

\section{VISÕES DE SI: MEMÓRIA E RESSENTIMENTO}

Logo, ao introduzir o leitor na narrativa das suas Memórias, Paschoal Lemme problematiza o estilo memorialístico, chamando a atenção para a dimensão relativista e precária da sua condição como expressão de exatidão. Explica que a evocação de um tempo passado é sempre imperfeita, uma vez que o homem que narra uma história já não é mais o homem que a viveu. Também considera difícil a tarefa de utilizar uma linguagem, um estilo e uma estrutura narrativa capazes de traduzir os múltiplos aspectos de uma situação ou circunstância vivida. Diz ainda que um momento lembrado potencialmente remete a outros tantos momentos, evoca emoções e sensações que a palavra não é capaz de alcançar. Pergunta-se sobre as razões que levam um indivíduo a contar a sua história e especula se as memórias conteriam um desejo de comunicação, uma preocupação educativa, uma justificativa diante de um incompreendido, um pretexto para colocar ideias em circulação, a expressão de uma personalidade egocêntrica, desabafos ou um esforço de colocar-se na história, não ficar aquém da vida. Além disso, confessa Lemme, "é impossível ser imparcial quando pretendemos ser juízes de nós próprios. (...) ninguém aceita na verdade, voluntariamente, apresentar-se mal, despir-se perante o mundo" (LEMME, 2004, p. 25, v. 1).

A problematização de Lemme em torno das possíveis razões que tornam as memórias pouco fidedignas tem uma razão de ser. Embora diga que "considerava suas ações e ideias inúteis e desimportantes", ao escrever as suas Memórias, "na condição de alguém que participou de importantes acontecimentos relacionados à história da educação e do ensino no Brasil", Lemme tinha a expectativa de que a sua obra fosse tomada como fonte documental na realização de "trabalhos de maior valia".

Diante da expectativa de Lemme, podemos dizer que a dimensão retrospectiva da escrita de si guarda um apelo prospectivo. A sua reminiscência é também a busca da sua permanência. Segundo Gomes (2004), a importância de sobreviver na memória de si e dos outros foi erigida no ambiente das sociedades modernas. Nessas sociedades, a necessidade de contar a sua própria história encontra-se sustentada pelo reconhecimento conferido à singularidade de cada um no interior do todo social e pelo sentimento de existir autonomamente em relação aos demais indivíduos. Ou seja, a percepção das emoções como sendo experiências internas, o cultivo de si e de suas vidas interiores, o sentimento de isolamento combinados ao reconhecimento de todos os cidadãos como livres e iguais, à sensação de possuir uma personalidade ímpar, à afirmação do triunfo do indivíduo, da sua razão e dos seus sentimentos terminou por conferir à vida individual uma importância digna de ser narrada.

Ocorre que, no decurso do processo civilizador, conforme Elias (1994), ao passo

que, pela razão, os indivíduos foram sendo liberados de concepções pré-científicas e mágico-míticas sobre si e a respeito de suas existências, eles também foram sendo sub- 
metidos a processos de individualização cada vez mais incisivos, profundos e difusos. Como produto típico do estilo de coexistência social, sobretudo nas sociedades nacionais complexas, emerge o sentimento de isolamento dos indivíduos. Assim, embora a vida individual tenha ganhado notoriedade na sociedade moderna, sentir-se, ao mesmo tempo, como um ser único e anônimo, é uma questão angustiante. Em função dessa angústia, Elias considera que as pessoas encontram dificuldades para se analisarem de forma distanciada; ou seja, sem lançarem mão de suas "fantasias protetoras". Segundo o autor, as fantasias protetoras, carregadas de imagens desejantes e temerosas, cumprem uma importante função social na construção das autoimagens dos indivíduos, porque os auxiliam a suportar as catástrofes da História, os sofrimentos causados entre os humanos e a insatisfação por não poderem controlar os seus destinos. ${ }^{12}$

Na complexa operação de produção do eu, chama a atenção o modo como Lemme lança mão de fantasias protetoras na construção da sua autoimagem. Para expressar o seu isolamento; isto é, a sua peculiaridade e o sentimento de existir internamente, Lemme colocou-se na rota de acontecimentos e nomes capazes de vincular a sua figura à ideia de homem do povo, voltado para as causas populares. Assim é que comparecem na sua retórica as indicações de que "nasceu numa pequena casa", "de uma rua insignificante", "numa semana maldita" de novembro de 1904 (em referência à Revolta da Vacina).

O ano de 1904 é considerado por muitos historiadores como verdadeiro marco divisório entre os séculos 19 e 20, se é que os séculos são passíveis de separações tão nítidas. (...) A era das grandes guerras mundiais e das revoluções, das imensas transformações verificadas na vida econômica, política e social, em todos os quadrantes do mundo. (...) Nessa "semana maldita", na apóstrofe indignada do poeta, em pleno desenvolvimento da revolta popular, num sábado, a 12 de novembro de 1904, mais ou menos às 18 horas, talvez apressado pelas circunstâncias e emoções do momento, nascia eu, numa pequena casa de uma rua insignificante - a Rua Augusta, n. 04 - na parte alta do lado esquerdo da Estação Méier ... O signo (está muito em moda sua utilização) era o de "escorpião", contraditório, com males e bens terríveis... (LEMME, 2004, p. $61,64-65$, v. 1).

Avaliou que o fato de ter nascido sob o signo de uma revolta popular possa ter acentuado nele a condição de incerteza daqueles que viveram no seu tempo. Diante das inseguranças da sua época, de "não ter nascido ou não ter sido educado para passar a vida em

12 Perspectiva correlata à ideia eliasiana das fantasias protetoras pode ser identificada na psicanálise por meio do sentido freudiano atribuído às ilusões. Segundo Eugène Enriquez (2005), Freud postulou que a exigência fundamental para a civilização perdurar é a de edificar Estados sólidos, capazes de oferecer um grande espaço para as ilusões no fundamento de toda crença a fim de obter, da parte dos indivíduos, a maior renúncia possível à satisfação (pelo menos imediata) das pulsões. No entanto, a vontade de poder dos Estados pode levar os indivíduos a fazer a guerra e a contribuir para o declínio e, às vezes, para a destruição da civilização. Diante dessa incerteza é que os indivíduos lançam mão das ilusões (religiosas, ideológicas, laborais etc.) com a finalidade de construir uma existência estável, forjando para si convicções que os protejam do desconhecido e do imprevisível. 
brancas nuvens", teve que fazer opções radicais que não lhe permitiram levar uma existência tranquila e segura ${ }^{13}$ (LEMME, 2004, p. 66, v. 1).

Do seu nome, Paschoal Lemme explica que o herdou do avô materno e que essa herança causou-1he embaraços durante toda a vida. "Sendo um nome pouco comum", afirma Lemme, "fazia-me objeto de atenção especial, quase sempre irônica, que feria minha sensibilidade de menino tímido, encabulado." E acrescenta:

(...) 'Paschoal... Lemme...' os dois emes inusitados do meu nome de família levavam o funcionário a dar a interpretação que lhe ocorria e a mais frequente era atribuir-me o codinome do chefe da Revolução Russa - Lenine - muito em destaque na época, lá pelos idos de 1917-1920, anos durante os quais eu prestava aqueles exames (LEMME, 2004, p. 47, v. 1).

Nutriu orgulho da sua ascendência italiana. Lemme destaca que a terra do seu pai e avós também foi a pátria "inigualável" de importantes figuras da humanidade.

\begin{abstract}
Sempre tive orgulho dessa ascendência italiana, (...) Já nos tempos atuais, um outro escritor de origem bem diversa - o russo Llya Ehrenbourg - em suas Memórias, com a mesma ternura e admiração, fala-nos assim da pátria das maiores figuras que a humanidade já produziu: um Virgílio, um Dante, um Leonardo da Vinci ou um Miguel Angelo (LEMME, 2004, p. 49, 51, v. 1).
\end{abstract}

Da mesma maneira, considerava a sua família uma das fundadoras e impulsionadoras do desenvolvimento do Méier; que na sua visão era a "capital" dos subúrbios da Central. Em função disso diz que chegou a reivindicar o nome do seu pai para uma praça do bairro por julgar que se tratava de um "direito da família Lemme e uma justa homenagem prestada ao chefe da família” (LEMME, 2004, p. 58, v. 1).

Paschoal Lemme foi educado sob os preceitos do espiritismo. Sentia-se diferente e se perguntava se a incursão pelo espiritismo é que tinha produzido nele a percepção de inadaptação da sua família em relação ao padrão comum das famílias de classe média.

Essa passagem pelo espiritismo deixou em todos nós, além desse desfecho

13 Além de apontar o ano do seu nascimento como um divisor de águas na história da humanidade, Lemme relaciona o ano de 1904 à inauguração de uma "Universidade Popular", no Rio de Janeiro. É provável que essa Universidade Popular tenha sido fundada pelo Centro das Classes Operárias. Segundo noticiado pela imprensa, a Universidade Popular do Centro das Classes Operárias tinha como finalidades promover a instrução, a educação e a emancipação do operariado. Além dos cursos e conferências, a Universidade Popular dispunha de livraria, biblioteca, museu social, consultório médico e jurídico e serviço de informações (JORNAL DO BRASIL, 19/03/1904, p. 3). Segundo Paulo Ghiraldelli Júnior (1986), tratou-se de uma iniciativa libertária bastante efêmera, apesar do clima de euforia em torno da sua fundação. Mais dados sobre a Instituição podem ser lidos no artigo "Movimento operário e educação popular na primeira república" (GHIRALDELLI JUNIOR, 1986). 
doloroso, ${ }^{14}$ uma certa inadaptação ao padrão comum das famílias de nossa classe. Eu, pelo menos, sempre senti essa singularidade em minha vida em contato com outras pessoas e nunca pude definir exatamente o caráter dessa diferença. Ou já éramos diferentes e a incursão pelo espiritismo foi apenas uma consequência? (LEMME, 2004, p. 145, v. 1).

Na sua narrativa, a cerimônia religiosa do seu casamento havia sido realizada "na Igrejinha de Santo Antônio dos Pobres, à Rua dos Inválidos, (...) na maior simplicidade". Diz também que sempre estranhou o fato de Carolina ter se casado com ele, "um civil, desprovido de atrativos", ao passo que Carolina tinha parentes e amigos nas Forças Armadas e frequentava festas promovidas por oficiais da Vila Militar (LEMME, 2004, p. 184,185, v. 1).

Em várias passagens da narrativa de si Lemme expressa a sua frustração por não ter podido atuar no cumprimento de alguma importante atividade quando havia a expectativa de que uma tarefa ou cargo lhe seriam reservados. Em tons de amargura e ironia, avalia que a sua dedicação e empenho foram recompensados com perseguição, inquérito, prisão e outras provações. Numa dessas passagens, Lemme termina por "confessar" que quando recebeu a incumbência de organizar e dirigir a educação de adultos, por meio dos cursos de continuação, aperfeiçoamento e oportunidade, ele esperava assumir "a função mais alta" de Superintendente da Educação Secundária e Geral e Técnica e do Ensino de Extensão; cargo esse confiado a Joaquim Faria Góes e de quem Lemme ficou subordinado "apenas" como seu assistente.

(...) Faria Góes, que não tinha qualquer contato anterior com os problemas específicos de educação e ensino, revelou-se um administrador competente fazendo brilhante carreira de educador, (...) concordei plenamente com Anísio Teixeira, quando resolveu investi-lo nas funções mais altas de Superintendente da Educação Secundária e Geral e Técnica e do Ensino de Extensão, quando esse cargo foi criado pela lei que transformou o Departamento de Educação em Secretaria Geral de Educação e Cultura. Todos os meus colegas estavam certos de que esse cargo seria entregue a mim, como um final de carreira, que deveria coroar todo o meu trajeto, desde os bancos escolares de uma escola profissional, até as responsabilidades do magistério nos cursos dessas escolas. Abri mão, porém, do cargo, quando senti as preferências de Anísio, e aceitei apenas a função de assistente de Faria Góes, prestando depois toda a minha colaboração quando fui designado para organizar e dirigir os cursos de extensão, continuação, aperfeiçoamento e oportunidade, subordinados àquela Superintendência, e que constituíam um dos grandes destaques da administração de Anísio Teixeira (LEMME, 2004, p. 127, v. 2).

14 O pai de Paschoal Lemme abandonou a família para viver com outra mulher - uma médium que frequentava a mesma casa espírita dos Lemme. O acontecimento foi traumático. Ao que parece, o pai de Lemme desapareceu repentinamente. Em 17 de junho de 1931, dois jornais de grande circulação (DIÁRIO CARIOCA e JORNAL DO BRASIL) divulgaram a nota “Onde está o dentista?", na secção de segurança pessoal da $4^{\mathrm{a}}$ Delegacia Auxiliar, pela qual pedia notícias a respeito do paradeiro de Antonio Lemme. 
Diante da privação de liberdade experimentada, avaliou ter sido injustiçado e rememora que aquilo que ele viu e ouviu na prisão só serviram para reforçar as suas conviç̧ões e afinidades em relação ao materialismo. Para reparar a sua honra e distinção, arranhadas pelos dezesseis meses que passou detido, recorda o apoio que recebeu do seu pai, valendo-se das suas fantasias protetoras.

\begin{abstract}
Creio mesmo que já na parte final de sua vida, e em decadência acentuada, dada as ilusões afetivas que alimentara e que perdera, orgulhava-se de nós, de nossas carreiras e até mesmo nossas ideias, um tanto radicais. Lembro-me bem que, indo me visitar quando eu amargava nas prisões da reação (1936-1937), não lamentou propriamente minha situação e parecia mesmo aprovar inteiramente minha atitude de resistência às iniquidades que os presos políticos sofriam naquela época sombria de nossa história (LEMME, 2004, p. 57, v. 1).
\end{abstract}

A partir da extração de algumas referências de Lemme em relação a si, temos que a construção da sua autoimagem sugere uma associação entre insignificância, pobreza, humildade, incerteza, injustiça, sofrimento, embaraço, luta, mérito, reconhecimento. Assim, para as fontes de anonimato de si com as quais se deparou ao longo da vida, Lemme respondeu com indicações de resistência e distinção próprias daqueles que "não nasceram ou foram educados para passar a vida em brancas nuvens".

Nesse jogo entre anonimato e distinção, Lemme se disse constrangido pelas ocasiões em que teve o seu nome confundido durante os exames preparatórios, mas, a bem da verdade, o seu nome não era confundido com o nome de uma pessoa qualquer. A simplicidade que descreve o local em que nasceu contrasta com a grandiosidade e importância histórica conferida àquele tempo. Percebendo-se como preterido em relação a Faria Góes, Lemme realça que os "cursos de extensão, continuação, aperfeiçoamento e oportunidade", organizados e dirigidos por ele, constituíam um dos grandes destaques da administração de Anísio Teixeira.

Em alguma medida, nesse jogo Lemme exprime a sua narrativa como a narrativa de um mito, ${ }^{15}$ para o qual a associação do seu nome à figura de Lenine pode ser entendida como recurso para ressaltar a sua imagem como sendo a de um homem virtuoso, identificado com o sofrimento dos pobres e oprimidos. Do mesmo modo, a exaltação das origens da sua ascendência vinculada ao nome de Dante, por exemplo, pode funcionar como uma maneira de destacar a sua imagem como sendo a de um homem insuspeito, com ativa participação na vida pública e que sofreu perseguições por não abrir mão das suas conviç̧ões. Assim, por meio da utilização de elementos da narrativa do mito, com Lenine e Dante, Lemme coloca-se entre aqueles que talvez ele julgasse ocuparem o mais alto escalão da representação da força, luta, capacidade intelectual e persistência diante da incompreensão e injustiça.

Além dos recursos da narrativa do mito na construção da autoimagem que pretendeu deixar registrado Lemme também acerta contas com a sua história, destaca e resguarda, lem-

15 A partir das considerações desenvolvidas por Jorge Ferreira (2002), a narrativa do mito diz respeito à construção de modelos exemplares de comportamentos que, em função disso, permitem que as sociedades interpretem sua realidade social e reflitam sobre a legitimidade do poder que as rege. 
bra e esquece, constrói e reconstrói, como típico de uma memória-monumento. Expressou com a sua reminiscência um desejo de permanência e reafirmação do existir. Por meio das suas fantasias protetoras, deu conta de rememorar a sua vida, de elaborar a sua existência e torná-la suportável. Podemos dizer que a construção da sua autoimagem é reveladora da atuação das pressões sociais sobre o seu processo de individualização. Isto é, uma construção que revela o modo como Lemme deu conta de forjar uma identidade para si no processo social.

Traços de ressentimento pontuam a narrativa memorialística de Paschoal Lemme. Essa marca não se parece com inveja, raiva, vingança, malícia ou ódio. Tampouco sugere uma escrita mal-humorada, sem motivos claros e definidos, voltada contra tudo e contra todos. A memória ressentida de Lemme é preponderantemente percebida no seu sentido social. Segundo David Konstan (2004), o ressentimento no seu sentido social pode emergir entre classes socialmente descontentes que perderam ou que estão perdendo a sua posição privilegiada, mas também pode ser encontrado nos Estados democráticos nos quais os cidadãos compartilham da igualdade política em concomitância com a existência da desigualdade social. Nesses termos, é possível dizer que as Memórias de Lemme constituem uma narrativa que remete a emoções derivadas de uma "frustração de longa duração"; ou seja, "da percepção de pertença a grupos em posição injustamente subordinadas em uma hierarquia de status" (KONSTAN, 2004, p. 61).

No entanto, ainda que o sentido social do ressentimento seja mais facilmente identificado na narrativa de Lemme, é difícil encontrar uma justa medida para circunscrevê-las. Embora Lemme "deslize" em algumas passagens das suas Memórias, não se trata de afirmar que ele pretendeu fixar uma autoimagem vitimada, que teve o mundo como seu opositor e requereu com a sua narrativa, uma reparação. O cotejo das suas Memórias com outras fontes demonstram que Lemme foi atuante e engajado, defendeu as suas posições toda vez que teve a oportunidade e, em outras ocasiões, ele próprio articulou as conveniências necessárias à exposição das suas ideias e projetos.

Ademais, não se trata de enquadrar os sentimentos de Paschoal Lemme ou de julgar as suas emoções. A palavra ressentida de Lemme parece ter sido o caminho que ele encontrou para expressar as suas lutas e crenças em circunstâncias que muitas das vezes não lhes foram favoráveis. Afinal, ser um educador e intelectual de esquerda, intimamente relacionado com o comunismo, não parece ter sido uma tarefa simples em alguns momentos da história brasileira. Nas suas Memórias, Lemme esforçou-se para demonstrar essa sua condição.

Desse modo, interessa aqui afirmar que o ressentimento, como característico da narrativa memorialística de Lemme, encontraria no individualismo das sociedades modernas um terreno sobre o qual sua narrativa pode ser compreendida. Nessa perspectiva, tal como sugere Elias (1994), a sua história é reveladora das tensões presentes na construção das autoimagens dos seres humanos como pessoas e como sociedade, quando consideramos que cada indivíduo é uma pessoa singular, com sentimentos e vivências únicas e é também um ser anônimo que existe, como todos os demais, numa sociedade de estrutura cambiável, cujas transformações históricas independem do planejamento e das intenções de qualquer um em particular. 


\section{CONSIDERAÇõES FINAIS}

Se considerarmos que Lemme aposentou-se em 1961, temos que ao longo de quase toda a sua trajetória profissional a educação de adultos ocupou um espaço significativo. Além de ter organizado e dirigido a educação de adultos no Distrito Federal, de ter sido preso sob a acusação de propagandear o comunismo num desses cursos e de ter se dedicado ao tema quando concorreu ao cargo de técnico em educação do MES, o mapeamento das redes de interdependência de Lemme, bem como, o confronto entre fontes permitiu tomar conhecimento da experiência da UP e de outras manifestações de Lemme em prol da educação de adultos. Dessa maneira, tal como a hipótese de investigação, a sua autêntica contribuição à questão da educação de adultos foi projetá-la ao nível dos grandes problemas nacionais atribuindo-a um lugar de destacada relevância no processo de democratização da sociedade com ideias, propostas e realizações concretas que ultrapassaram aquelas ancoradas na defesa de destinar aos adultos uma educação elementar.

O estudo da figuração de Paschoal Lemme em sua interdependência com outras figuras sociais no processo de militância e produção intelectual em prol da educação de adultos demonstrou que as suas ideias anteciparam temas para a época em que foram publicizadas. Além da sua importância para a educação de adultos no âmbito da instrução pública do Distrito Federal, Lemme também foi um educador e intelectual de expressão junto ao PCB. Particularmente no tocante aos problemas da educação de adultos, Lemme teve no partido o apoio necessário à divulgação das suas ideias e propostas assim como para a materialização do seu pensamento.

No entanto, em conformidade com a proposição eliasiana, o desenvolvimento do conhecimento - inscrito no desenvolvimento mais amplo das sociedades - carrega consigo tensões e conflitos específicos capazes de validar e colocar uma ideia em circulação ou de banir, reprimir e "fazer esquecer" formas de pensamento em função dos diferenciais de poder distribuídos entre os grupos sociais. Como tal, a identificação de Lemme com a ideologia marxista e sua proximidade com os comunistas concorreram para interditar a penetração das suas posições em circuitos sociais mais amplos. E assim sendo o modo de organizar a oferta pública de educação destinada aos adultos e o papel a ser desempenhado pela educação de adultos na democratização da sociedade, tal como formulados por Lemme, não desfrutaram de larga aceitação.

Acresce ao fato que a implantação da CEAA, seja pelos recursos que mobilizou, abrangência que atingiu e também por coadunar com os propósitos políticos e ideológicos de grupos mais privilegiados na escala de poder (PAIVA, 2003), terminou por fixar a Campanha como um marco nacional das ações públicas de educação endereçadas aos adultos. Com isso, a inserção de Paschoal Lemme na educação de adultos acabou tornando-se invisibilizada.

Ao fim deste trabalho, o raciocínio utilizado por Marta M. Chagas de Carvalho (1989) para explicar os motivos que expulsaram da investigação em história da educação os grupos em confronto e o significado político das divergências presentes nos círculos educacio- 
nais após 1930 parece adequado para elucidar as razões que obstruíram o desenvolvimento de pesquisas destinadas a tratar das relações de outros intelectuais com a educação de adultos. Ocorre que, segundo a autora, a historiografia da educação brasileira foi amplamente influenciada pela narrativa de Fernando de Azevedo em sua obra "A cultura Brasileira". Entretanto, tal narrativa foi erigida com base na polaridade "velho X novo"; isto é, numa perspectiva ascendente e linear do novo (representado pelo movimento de renovação pedagógica) sobre o velho (representado pelas formas educacionais tradicionais). Como tal, não reservou espaço para ideias conflitantes e disputas existentes "na zona de pensamento perigoso" (zona na qual as ideias de Paschoal Lemme estiveram situadas).

Por analogia à assertiva de Carvalho, é possível considerar que a pesquisa sobre a história da educação de adultos tenha assumido a obra de Paulo Freire como referência de ideias e de ações progressistas desenvolvidas nos anos de 1960 em oposição às campanhas nacionais de educação de adultos dos anos de 1940-50, e posteriormente, ao MOBRAL, modelo instituído no regime militar. Com isso, a produção do conhecimento acerca da história da educação dos trabalhadores no Brasil terminou por reiterar os anos de 1960 como marco de origem de um pensamento avançado sobre a educação de adultos e de práticas educativas de resistência às campanhas oficiais. Ou seja, o enredo historiográfico acerca da educação de adultos foi informado pela polaridade "regulação X emancipação" a partir de uma definição temporal e de experiências pedagógicas específicas. Nesse processo Paschoal Lemme, que em 1947 se encontrava invisibilizado, terminou esquecido.

Mas ao longo das duas décadas que precederam a instalação da CEAA, enquanto na cena política o trabalhador fora disputado como interlocutor por variados segmentos, no contexto educacional diferentes propostas e modos de pensar a educação do adulto analfabeto ou pouco escolarizado foram postas em circulação. Em relação a Lemme, nas diferentes ocasiões em que se pronunciou sobre o tema, atribuiu um lugar de destacada relevância à educação de adultos no processo de democratização da sociedade. A sua militância em favor da educação de adultos baseou-se na articulação entre educação, participação política e melhoria das condições econômicas dos pobres. E assim sendo, ao longo da sua trajetória, Paschoal Lemme também ofereceu importantes contribuições para a escrita da história da educação dos trabalhadores no Brasil.

\section{REFERÊNCIAS}

ARAÚJO, Moisés X. de. Chave da leitura (para adultos). Acervo da Fundação Biblioteca Nacional - Rio de Janeiro/Brasil, 1946.

ARQUIVOS DA POLÍCIA POLÍTICA. Comunismo. Relatório da Polícia Política, 1937. Pastas: 1785, 1321, 1573. Disponível em http://www.siaapm.cultura.mg.gov.br. Acesso 23/10/2013.

BACKHEUSER, Everardo. Tese 14. Educação de Adultos. Convenção Educacional Fluminense, 1936. Arquivo Paschoal Lemme (PROEDES/UFRJ). 
BEISIEGEL. Celso de Rui. Estado e educação popular - Um estudo sobre a educação de adultos, 1. a reedição. Brasília: Liber Livro, 2004.

Diário de Notícias, Rio de Janeiro (segunda seção), p. 3, 19 de abril de 1952.

ELIAS, Norbert. A sociedade dos indivíduos. Rio de Janeiro: Zahar, 1994.

. Mozart - Sociologia de um gênio: Rio de Janeiro: Zahar, 1995.

. A sociedade de Corte: investigação sobre a sociologia da realeza e da aristocracia de corte. Rio de Janeiro: Zahar, 2001.

ENRIQUEZ, Eugène. Psicanálise e ciências sociais. Ágora. Rio de Janeiro, v. VIII, n. 2, jul./dez. 2005.

FAVORETO, Aparecida. Marxismo e educação no Brasil (1922-1935): o discurso do PCB e de seus intelectuais, 2008. Tese (Doutorado em Educação) - Faculdade de Educação da Universidade Federal do Paraná, Curitiba, 2008.

FERREIRA, Jorge. Prisioneiros do mito: cultura e imaginário político dos comunistas no Brasil (1930-1956). Niterói: EdUFF: Rio de Janeiro: MAUAD, 2002.

GHIRALDELLI JÚNIOR, Paulo. Movimento operário e educação na primeira república. Cad. Pesquisa. São Paulo, n. 57, mai., 1986.

GOMES, Ângela de Castro (Org.). Escrita de si - Escrita da história. Rio de Janeiro: Editora FGV, 2004.

GOMES, Ângela de Castro. A invenção do trabalhismo, 3. ed. Rio de Janeiro: Editora FGV, 2005.

Imprensa Popular, Rio de Janeiro, p. 4, 20 de abril de 1952.

Jornal do Brasil, Rio de Janeiro, p. 3, 19 de março de 1904.

Jornal do Brasil, Rio de Janeiro, p. 8, 26 de julho de 1933.

KONSTAN, David. Ressentimento - história de uma emoção. In: BRESCIANI, Stelle, NAXARA, Márcia. Memória e (res)sentimento: indagações sobre uma questão sensível. Campinas, SP: Editora da UNICAMP, 2004.

LE GOFF, Jacques. História e Memória. Campinas: Editora da UNICAMP, 1990.

LEMME, Paschoal. Memórias de um educador - Paschoal Lemme, 2 ed. Brasília: INEP, 2004.

. Educação de Adultos. Conferência realizada a convite no Centro dos Professores das escolas noturnas municipais do Distrito Federal, 1937a. Arquivo Paschoal Lemme (PROEDES/UFRJ).

. A educação de adultos no estado do Rio de Janeiro. Ante-projeto da organização da educação de adultos no estado do Rio de Janeiro. Assembleia Legislativa do Estado 
do Rio de Janeiro, 1937b. Acervo digital Paschoal Lemme. Disponível em www.paschoallemme.com.br. Acesso em 28/10/2014.

. Educação de Adultos - uma experiência de cursos de continuação, aperfeiçoamento e oportunidade realizada no Distrito Federal. Tese apresentada no concurso para técnico em educação do Ministério da Educação e Saúde, 1938. Arquivo da Associação Brasileira de Educação (ABE/RJ).

LOURENÇO FILHO, Manuel Bergström. Plano de ação supletiva por parte da União na educação primária de todo o paiz. V Conferencia Nacional de Educação, 1933. Arquivo Paschoal Lemme (PROEDES/UFRJ).

MOTTA, Rodrigo Patto Sá. Em guarda contra o perigo vermelho: o anticomunismo no Brasil (1917-1964). São Paulo: Perspectiva: FAPESP, 2002.

MOVIMENTO. Revista do Club de Cultura Moderna. Rio de Janeiro, n. 3, 1935. Arquivo Edgard Leuenroth (AEL/UNICAMP).

PAIVA, Vanilda. História da Educação Popular no Brasil - Educação popular e Educação de Adultos, 6. ed. São Paulo: Edições Loyola, 2003.

PRIORE, Mary del. Do outro lado: a história do sobrenatural e do espiritismo. São Paulo: Planeta, 2014.

RICOEUR, Paul. A memória, a história, o esquecimento. Campinas, SP: Editora da UNICAMP, 2007.

SAVIANI, Dermeval. Paschoal Lemme no manifesto: um estranho no ninho dos Pioneiros? In: Escola e democracia. Campinas: Autores Associados, 2008 (Edição comemorativa).

SIRINELLI, Jean-François. Os intelectuais. In: RÉMOND, René. Por uma história política (Org.), 2 ed. Rio de Janeiro: Editora FGV, 2003.

Tribuna Popular, Rio de Janeiro, p. 3, 2 de fevereiro de 1946.

TRINDADE, Helgio. Integralismo. In: ABREU, Alzira Alves de, BELOCH, Israel, LATTMAN-WELTMAN, Fernando, LAMARÃO, Sergio Tadeu de Niemeyer. Dicionário Histórico-biográfico brasileiro pós-1930. Rio de Janeiro: Editora FGV; CPDOC, 2001 (vol. III).

VEIGA, Cynthia Greive. História cultural e psico-história: a discussão historiográfica de Karl Lamprecht e Norbert Elias. In: BELCHIOR, Luna HalabI, PEREIRA, Luisa Rauter, MATA, Sérgio Ricardo (Orgs.). Anais do $\mathbf{7}^{\mathbf{0}}$. Seminário Brasileiro de História da Historiografia "Teoria da história e história da historiografia: diálogos Brasil-Alemanha". Ouro Preto: EdUFOP, 2013.

VIDAL, Diana Gonçalves (Org.). Educação e Reforma - o Rio de Janeiro nos anos 19201930. Belo Horizonte: Argvmentvm: São Paulo: CNPq: USP, Núcleo Interdisciplinar de Estudos e Pesquisas em História da Educação, 2008. 
WAIZBORT, Leopoldo (Org.). Dossiê Norbert Elias. São Paulo: Editora da Universidade de São Paulo, 1999.

\section{DAdOS DA AUTORA}

\section{CRISTIANE FERNANDA XAVIER}

Doutora em Educação pela Universidade Federal de Minas Gerais. Professora adjunta da Universidade Federal de Alfenas. Alfenas/MG - Brasil. cristianefx@yahoo.com.br

Submetido em: 07-08-2017

Aceito em:7-11-2017 